Nevertheless, the book is a very valuable one, giving, as it does, a range of information which would be quite impossible to find without a great deal of reading of scattered research journals. I have already found the volume of considerable value as a source of information to illustrate lectures on a variety of topics. Within a period of two weeks, use has been made of the tables on the nutritional requirements of lower Algae, the physical and chemical characteristics of antibiotics, and the expectation of life in various countries.

Two criticisms are valid, however, since they affect the utilization of the book. First, the tables are very complex with a large number of qualifying or descriptive footnotes, and can only be interpreted with careful study and much thought. Secondly, the value of a handbook of this type is directly proportional to the fullness and accuracy of the table of contents and index. For the purposes of this review, I tried to find the frequency of blood groups in the population of the United Kingdom or the United States. There is no entry in the index under either of the countries nor is there one under "Groups" or "Blood Groups", and under "Blood" there are thirty-three page references. The data were eventually found in a table headed "Blood Groups and Factors" in the section on genetics, cytogenetics and reproduction.

In the index, one finds under "Pine(s)", twentyeight references, and under "Pinus spp.", twentyseven references, but when these are compared, there are only nineteen in common. One would have thought that the similarity between "Pinus spp." and "Pine(s)" was sufficiently great not to justify this amount of discrimination.

With all its drawbacks, this volume is a bold effort to produce a handbook of use to all scientists working with living material. It is no fault of the editor or the contributors that the material is difficult to get into tabular form, and as a source-book of raw data it is indeed welcome. It is to be hoped that future editions can be more fully indexed or that the subsectional headings may be put in alphabetical or at least non-random order. Personal prejudice makes me object to a book weighing $4 \mathrm{lb}$. and messuring 9 in. $\times 11$ in. being called a "Handbook".

A. R. Gemmeit

\section{GEOPHYSICS AND GEOCHEMISTRY}

Physics and Chemistry of the Earth

Edited by L. H. Ahrens, Prof. Kalervo Rankama and S. K. Runcorn. Vol, 1. (Progress Series.) Pp. viii + 317. (London: Pergamon Press, Ltd., 1956.) 55s.

7 HE study of the Earth draws its methods from nearly all branches of science. There is therefore, as the editors of this collection say in their preface, a special need for critical reviews of many of the diverse topics that make up the Earth sciences. In this field everyone is, in a large degree, an amateur; no one knows enough to consider the great problems of geology as they really are and in the light of all the relevant information. Everyone needs a guide, such as these articles give, through the interpenetrating mazes of physics, chemistry, mineralogy and astronomy.

The book is the first of an annual series. It contains eight articles; the first, by Sir Harold Spencer Jones, discusses the origin of the solar system. The various catastrophic and accretion theories are reviewed with the conclusion that "the problem of formulating a satisfactory theory of the solar system is still not solved". The great difficulty is to devise a course of events that will lead to nearly all the mass being in the sun and nearly all the angular momentum in the orbital motion of the planets. Alfvén has suggested that this is a magneto-hydrodynamic effect, but some of the assumptions needed to produce the result are far from plausible.

The second article is by $J$. Verhoogen and discusses temperatures within the Earth. Verhoogen emphasizes the undesirability of calculating these by applying the theory of thermal conduction to an assumed initial state, since this introduces the uncertainties surrounding the origin and early history of the Earth. Alternative estimates depending on the melting point of an iron core and on the electrical conductivity within the Earth are to be preferred. $\mathrm{He}$ concludes that a temperature of $3,000^{\circ} \mathrm{K}$. at the core boundary is likely. 'This seems to me near the lower limit of possibly acceptable solutions.

L. H. Ahrens reviews determinations of the ages of rocks by the uranium-lead, potassium-argon and rubidium-strontium methods. The causes of dis: crepancies between the ages depending on the use of different combinations of lead and uranium ages are discussed. It is concluded that these are mainly due to loss of lead. An article on "Seismology and the Broad Structure of the Earth's Interior" by K. E. Bullen brings together the work that he, Jeffreys, Gutenberg and others have done on the distribution of elasticity and density within the Earth.

A long article by $R$. Hide discusses the hydrodynamics of the Earth's core; in the main this is directed to the explanation of the Earth's magnetic field. The problem is one of exceptional difficulty since, in addition to the inaccessibility of the core and the uncertainties about its constitution, temperature and electrical properties, there are the great mathematical difficulties of magneto-hydrodynamics. The diverse lines of evidence by which the relevant quantities can be estimated are well summarized. The dynamo and thermo-electric theories of the Earth's field are described, the author showing, on the whole, a preference for the former.

In the sixth article, R. Roy and O. F. Tuttle discuss investigations under hydrothermal conditions. It has long been known that the presence of water and other volatile constituents greatly modifies the behaviour of silicates at high temperatures. It is therefore very desirable that experiments should be made in the presence of water. It is only in the past few years that methods have been developed for applying high pressures and high temperatures simultaneously to such systems. The results are of great importance for an understanding of the processes occurring in the formation of rocks and of ore bodies. This review of a rapidly developing and complicated subject is most welcome.

The seventh article is a review by C. W. Correns of the geochemistry of the halogens. The editors state that such reviews of a group of elements will be a regular feature of these volumes. This article is largely a recital of facts, and is perhaps less readable than most of the rest of the book. The last article is a review of recent work on geochemistry in the U.S.S.R., containing an extensive bibliography.

Most of the subjects chosen for this book are developing rapidly and all are worth reviewing; the whole collection should stimulate interest in the physics and chemistry of the Earth.

E. C. BULLARD 